\title{
SEBARAN PENGGUNAAN LAHAN PERTANIAN DI KOTA TARAKAN DAN PREDIKSI POTENSI BAHAYA EROSI BERBASIS (SIG)
}

\author{
Nur Indah Mansyur ${ }^{1}$, Achmad Ilham Ramdani ${ }^{1}$ \\ ${ }^{1}$ Jurusan Agroteknologi, Fakultas Pertanian, Universitas Borneo Tarakan \\ E-mail: nurindah.mansyur@gmail.com
}

Diterima : 14 Juni 2021

Disetujui : 15 Agustus 2021

\begin{abstract}
Land use analysis is useful to identify the mechanisms of changes that occur in a land through a spatial approach in the Geographical Information System. The spatial approach is carried out by using the Arcgis program to analyze geographic data into map units. This study aimed to (1) determine the design of a Geographical Information System (GIS) in an inventory of the use and erosion potential hazards of agricultural land in Tarakan, and (2) inform the use and erosion potential hazards of agricultural land in Tarakan. this study took spatial data from the Public Works and Spatial Planning Office (DPUTR) of Tarakan, Digital Elevation Model (DEM) data to analyze the slope and height of Tarakan and field surveys using GPS. The results showed that the area of agricultural land use in Tarakan in general was $75.33 \%$, dominated by forest land use $38.91 \%$, non-residental open land $25.72 \%$, agriculture $9.35 \%$ and plantation land $1.35 \%$. In the land use system, it was never separated from the type of land cover. There were 10 types of land cover in Tarakan including urban forest, dry land forest, swamp/peat forest, mixed garden, dry land/fields, open land, shrubs, orchid botanical gardens, meadows and rice fields. Tarakan had the potential for erosion hazards which could be seen from the slope factor. From 2012-2020, there was an erosion of the area of the slope in each class, namely flat, sloping, steep, rather steep and very steep as well as a reduction in height from 124 MASL in 2012 to 107 MASL in the year 2020. With the existence of land cover and the potential danger of erosion, the land management approach in Tarakan must prioritize aspects of land intensification and conservation, so that the ecosystem can be maintained in a sustainable manner.
\end{abstract}

Keywords : Land Use, Geographical Information System (GIS), Erosion Hazard Potential

\begin{abstract}
ABSTRAK
Analisis penggunaan lahan berguna untuk mengidentifikasi mekanisme perubahan-perubahan yang terjadi pada suatu lahan melalui pendekatan spasial dalam Sistem Informasi Geografis. Pendekatan spasial dilakukan dengan menggunakan program ArcGIS untuk menganalisis data geografis ke dalam satuan peta. Penelitian ini bertujuan untuk (1) mengetahui rancangan Sistem Informasi Geografis (SIG) dalam inventarisasi penggunaan dan potensi bahaya erosi lahan pertanian di Kota Tarakan, dan (2) menginformasikan penggunaan dan potensi bahaya erosi lahan pertanian di Kota Tarakan.. Penelitian ini mengambil data spasial dari Dinas Pekerjaan Umum dan Tata Ruang (DPUTR) Kota Tarakan, data Digital Elevation Model (DEM) untuk menganalisis kemiringan lereng serta ketinggian tempat Kota Tarakan dan survei lapangan menggunakan GPS. Hasil penelitian menunjukkan bahwa luas penggunaan lahan di Kota Tarakan secara umum $75,33 \%$, didominasi lahan hutan $38,91 \%$, lahan terbuka non pemukiman $25,72 \%$, pertanian secara khusus 9,35\% dan lahan perkebunan 1,35\%. Tutupan lahan di Kota Tarakan terdapat 10 jenis tutupan meliputi hutan kota, hutan lahan kering, hutan rawa/gambut, kebun campuran, tegalan/ladang, lahan terbuka, semak belukar, kebun raya anggrek, padang rumput dan sawah. Kota Tarakan memiliki potensi bahaya erosi yang dapat dilihat dari faktor kemiringan lereng. Selama tahun 2012 hingga tahun 2020 terjadi pengikisan luas kemiringan lereng di setiap kelasnya yaitu datar, landai, curam, agak curam dan sangat curam. Terjadinya pengurangan ketinggian tempat dari 124 mdpl di tahun 2012 menjadi 107 mdpl di tahun 2020. Dengan adanya tutupan lahan dan potensi bahaya erosi tersebut maka pendekatan pengelolaan lahan di Kota Tarakan harus lebih mengedepankan aspek intensifikasi dan konservasi lahan, agar ekosistem dapat terpelihara secara berkelanjutan.
\end{abstract}

Kata kunci : Penggunaan Lahan, Sistem Informasi Geografis (SIG), Potensi Bahaya Erosi

\section{PENDAHULUAN}

Penggunaan lahan memiliki sifat yang dinamis, artinya penggunaan lahan akan selalu berubah. Faktor utama terjadinya perubahan penggunaan lahan dari waktu ke waktu adalah bertambahnya jumlah penduduk. Dengan bertambahnya jumlah penduduk akan mengakibatkan kebutuhan ruang pemukiman semakin bertambah dan ruang pertanian semakin menurun (Faddel, 2019). Untuk mendukung ketahanan pangan wilayah dan nasional, maka 
sumberdaya lahan merupakan faktor pembangunan pertanian yang sangat penting untuk diperhatikan. Data potensi sebaran dan keadaan eksisting dari lahan menjadi salah satu acuan dalam pengembangan dan pemanfaatan lahan.

Tarakan merupakan salah satu wilayah di Kalimantan Utara, berbentuk pulau dengan luas wilayah sekitar $250,80 \mathrm{~km}^{2}$ dan jumlah penduduk sekitar 239.787 jiwa (BPS Provinsi Kalimantan Utara, 2019). Kegiatan budidaya pertanian di Kota Tarakan telah menggunakan berbagai lahan pada berbagai lokasi, sehingga perlu dilakukan inventarisasi data penggunaan lahan pertanian. Kegiatan inventarisasi penggunaan lahan pertanian di Kota Tarakan akan membantu dalam melihat potensi untuk pengembangan pertanian maupun potensi terjadinya degradasi lahan. Proses inventarisasi penggunaan lahan dan deteksi potensi degradasi lahan sangat memerlukan SIG karena sistem ini memiliki validitas yang sangat tinggi dan dapat dipertanggung jawabkan karena Sistem Informasi Geografis (SIG) dirancang khsusus dengan data geospasial untuk menggambarkan secara detail keadaan suatu kawasan dengan peruntukkan apapun. (Sunartomo, 2011). Tujuan penelitian ini adalah untuk mengetahui dan menginformasikan penggunaan lahan pertanian potensi bahaya erosi di Kota Tarakan dalam rancangan SIG.

\section{METODE}

Penelitian dilaksanakan di Kota Tarakan pada bulan Oktober sampai dengan Desember 2020. Penelitian ini merupakan penelitian deskriptif kualitatif dan mendeskripsikan fokus penelitian (objek penelitian) yaitu penggunaan lahan dan potensi bahaya erosi berdasarkan data yang diperoleh dari hasil survey lapangan dan Analisis Spasial. Data survey lapangan dilakukan dengan mengambil titik koordinat pada wilayah tutupan lahan dengan obyek penggunaan lahan pertanian menggunakan Global Positioning System (GPS) dan Avenza Maps. Analisis spasial dilakukan dengan menggunakan Software ArcGIS 10.8 pada data Digital Elevation Model DEM) dan data spasial tutupan lahan dari Dinas Pekerjaan Umum dan Tata Ruang (DPUTR) Kota Tarakan. Analisis data dilakukan dengan Memetakan tipe penggunaan lahan dan tutupan lahan dengan tabulasi luasan lahan di kota Tarakan serta data potensi bahaya erosi dengan menganalisis faktor ketinggian tempat dan kelerengan dari tahun 2012, 2014,2016,2018 dan 2020.

\section{HASIL DAN PEMBAHASAN}

\section{Penggunaan Lahan Pertanian di Kota Tarakan} Penggunaan lahan merupakan kajian dalam penelitian ini, kriteria penilaian persentase penggunaan lahan di Kota Tarakan dalam penelitian ini didasarkan pada luas dari jenis penggunaan lahan tersebut dan difokuskan pada lahan pertanian yang mencakup kawasan budidaya, kawasan hutan, lahan terbuka, dan termasuk juga kawasan konservasi. Berdasarkan data dari Dinas Pekerjaan Umum dan Tata Ruang Kota Tarakan (DPUTR), jenis penggunaan lahan untuk pertanian di Kota Tarakan disajikan dalam Gambar 1.

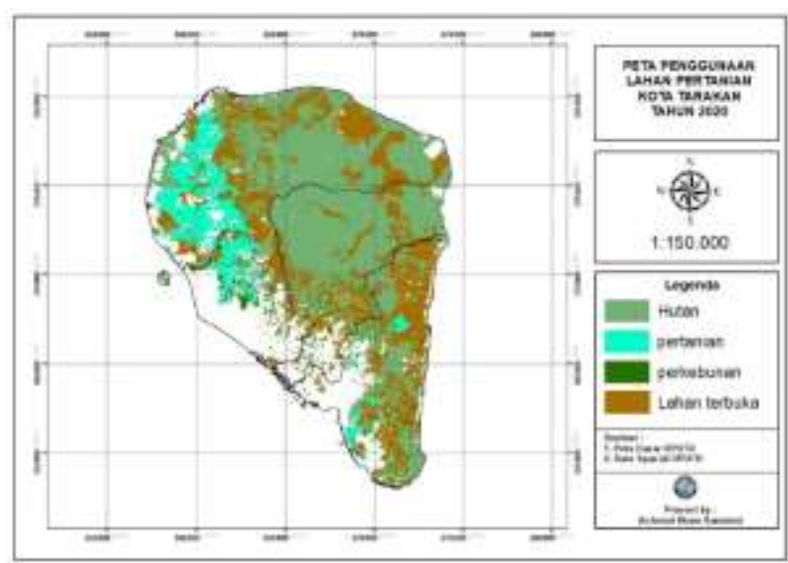

Gambar 1. Peta penggunaan lahan pertanian di Kota Tarakan (Sumber : DPUTR Kota Tarakan, 2020)

Penggunaan lahan pertanian di Kota Tarakan pada penelitian ini terdiri atas 4 jenis penggunaan lahan dengan total persentase luas $75,33 \%$ dari luas keseluruhan Kota Tarakan (Tabel 1). Penggunaan lahan pertanian yang dikhususkan dalam usaha budidaya masih tergolong kecil dengan persentase 
9,35\% dari luas keseluruhan Kota Tarakan. Penggunaan lahan di Kota Tarakan sebagian besar berupa kawasan hutan dan lahan terbuka, khusus kawasan hutan merupakan kawasan konservasi mutlak, artinya ekosistem dan keragaman hayati yang terdapat pada lahan tersebut harus dimanfaatkan secara bijak dan sesuai dengan proporsi kawasan tersebut. Jika memungkinkan untuk dilakukannya ekstensifikasi lahan maka lahan terbuka dengan beberapa kriteria tutupan lahan tertentu dapat menjadi opsi dalam pemanfaatannya dengan tetap memperhatikan aspek konservasi yang tepat. Konservasi menjadi bagian penting dalam menjaga keseimbangan alam agar tetap lestari (Arsyad, 2010).
Tabel 1. Luas Penggunaan Lahan Pertanian di Kota Tarakan

\begin{tabular}{cc}
\hline Penggunaan Lahan & Persentase Luas (\%) \\
\hline Hutan & 38,91 \\
\hline Perkebunan & 1,35 \\
\hline Pertanian & 9,35 \\
\hline Lahan Terbuka & 25,72 \\
\hline Total & 75,33 \\
\hline
\end{tabular}

Sumber : Pengolahan data analisis raster (2020)

\section{Sebaran Tutupan Lahan}

Tutupan lahan merupakan hasil pengaturan atau aktivitas manusia pada lahan tersebut (BSN, 2014). Sebaran dan luas tutupan lahan pada setiap kecamatan di Kota Tarakan disajikan dalam Gambar 2 dan Tabel 2.

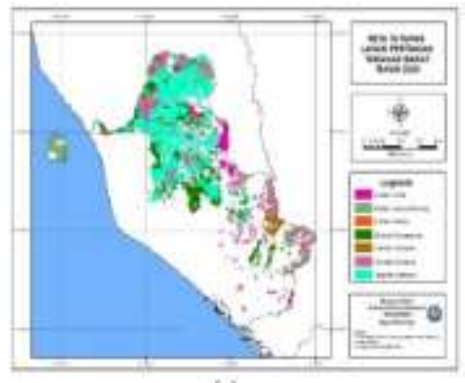

(a)

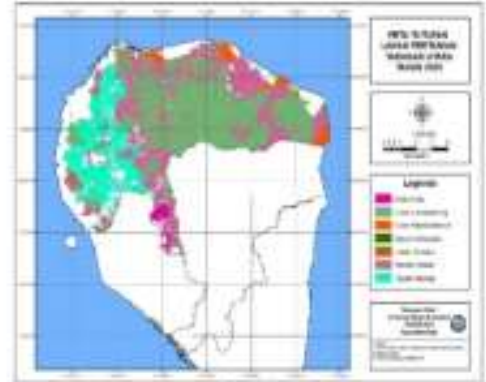

(d)

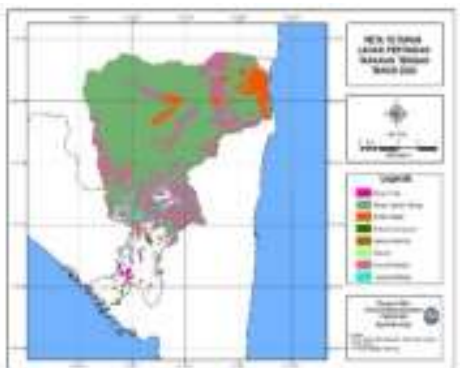

(b)

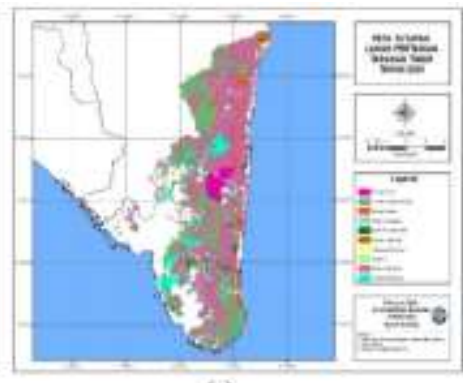

(c)

Gambar 2. Peta Sebaran Tutupan Lahan (a) Tarakan Barat, (b) Tarakan Tengah,

(c) Tarakan Timur, (d) Tarakan Utara dan (e) Kota Tarakan (Sumber : hasil analisis spasial, 2020)

Data sebaran tutupan lahan pada Tabel 2 menunjukkan bahwa terdapat dua wilayah kecamatan yang memiliki eksistensi dalam bidang budidaya yaitu Tarakan Timur dan Tarakan Utara. Didukung dengan luas tutupan lahan tegalan 1504,82 ha dan kebun campuran 6,12 ha untuk Kecamatan Tarakan Utara sedangkan Kecamatan Tarakan Timur luas tutupan lahan tegalan 297,115 ha, kebun campuran 92,67 ha dan sawah 13,837 ha. Dapat dilihat bahwa suplai dari sektor pertanian sebagian besar berasal dari Kecamatan Tarakan Timur, kemudian dari sektor perkebunan Kecamatan Tarakan Timur lebih unggul dari segi luas penggunaan lahan, sedangkan dari sektor hortikultura kecamatan Tarakan Utara menjadi suplai terbesar di Kota Tarakan 
Tabel 2. Luas Tutupan Lahan Pertanian Kota Tarakan

Luas Tutupan Lahan Pertanian di Kota Tarakan (Ha)

\begin{tabular}{ccccc}
\hline Jenis Tutupan Lahan & Tarakan Barat & Tarakan Tengah & Tarakan Timur & Tarakan Utara \\
\hline Hutan Kota & 41,18 & 33,1 & 128,25 & 104,5 \\
\hline Hutan Lahan Kering & 92,21 & 3591,2 & 1310,2 & 3818,99 \\
\hline Hutan Rawa Gambut & 1,42 & 277,3 & 91,68 & 268,62 \\
\hline Kebun Campuran & 201,15 & 38,14 & 92,67 & 6,12 \\
\hline Tegalan/Ladang & 457,78 & 70,71 & 297,11 & 1504,82 \\
\hline Lahan Terbuka & 23,68 & 14,58 & 17,9 & 86,26 \\
\hline Semak Belukar & - & 1238,26 & 2271,46 & 2542,09 \\
\hline Kebun Raya Anggrek & - & - & 0,87 & - \\
\hline Padang Rumput & - & - & 9,25 & - \\
\hline Sawah & - & 0,5 & 13,83 & -
\end{tabular}

Sumber : Data olahan analisis raster (2020)

Pada kecamatan Tarakan Tengah dan Tarakan Barat juga memiliki potensi dalam sektor tersebut akan tetapi eksistensinya tidak sebesar dari dua kecamatan sebelumnya, hal ini disebabkan oleh Tarakan Tengah dan Barat merupakan daerah dengan sebaran penduduk yang tinggi sehingga penggunaan lahan sebagian besar berupa pemukiman, selain itu sebagian masuk kedalam kawasan konservasi hutan dan mangrove, sehingga hal inilah yang menyebabkan dua kecamatan ini memiliki penggunaan lahan dibidang budidaya cukup kecil. Kecamatan Tarakan Utara dan Tarakan Timur memiliki tutupan lahan budidaya pertanian lebih luas disebabkan oleh dua faktor utama yaitu budaya masyarakat yang biasa bercocok tanam menyebabkan penggunaan lahan secara intensif dilakukan untuk budidaya pertanian dan ketersediaan lahan yang memadai untuk digunakan sebagai upaya pengelolaan kegiatan pertanian.
Potensi bahaya erosi merupakan perkiraan terjadinya erosi yang ditunjukkan oleh faktorfaktor dan fenomena yang mendukung. Kota Tarakan berpotensi untuk terjadi erosi, seperti data yang dapat dilihat, bahwa penurunan ketinggian dan juga luas di setiap dua tahun sekali menggambarkan potensi terjadinya bahaya erosi. Menurut Arsyad (2010). Tanah yang tererosi akan memiliki kemunduran sifat-sifat kimia dan fisika tanah, seperti kehilangan kandungan unsur hara maupun kehilangan ketahanan penetrasi tanah (Arsyad, 2010).

Data pada Tabel 3 menunjukkah bahwa kemiringan lereng setiap dua tahun sekali mengalami penurunan dan kenaikan dari segi luasan. Kenaikan dan penurunan tersebut disebabkan oleh terjadinya kehilangan tanah dari setiap kelas kemiringan lereng menuju ke kelas selanjutnya, sebagai contoh tanah pada kriteria kemiringan sangat curam yang terkikis akan terangkut menuju daerah kemiringan lereng satu atau beberapa tingkat dibawahnya (curam, agak curam, landai ataupun datar).

\section{Potensi Bahaya Erosi}

Tabel 3. Luas Kemiringan Lereng Kota Tarakan

\begin{tabular}{cccccc}
\hline \multirow{2}{*}{ Tahun } & \multicolumn{5}{c}{ Luas (Ha) } \\
\cline { 2 - 6 } & Datar & Landai & Agak Curam & Curam & Sangat Curam \\
\hline 2012 & 7285,41 & 4640,31 & 4467,10 & 5938,87 & 2091,97 \\
\hline 2014 & 8734,93 & 5716,33 & 5071,58 & 4642,77 & 675,60 \\
\hline 2016 & 15159,68 & 5422,65 & 3516,51 & 733,46 & 11,79 \\
\hline 2018 & 7159,78 & 4605,22 & 4498,70 & 5973,30 & 2070,49 \\
\hline 2020 & 9684,40 & 7092,43 & 5075,01 & 2397,40 & 381,01 \\
\hline
\end{tabular}

Sumber : Data olahan analisis raster (2020) 

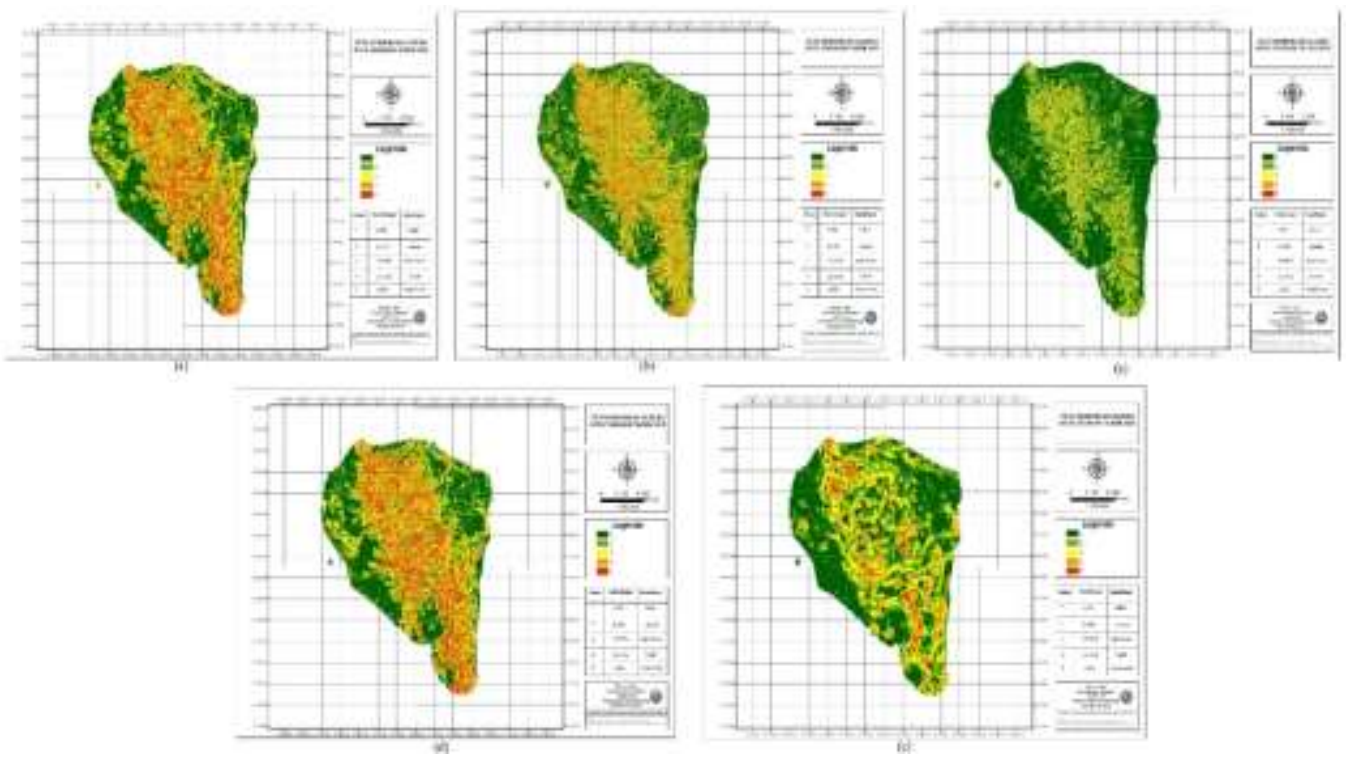

Gambar 3. Peta kemiringan lereng Kota Tarakan (a) Tahun 2012, (b) Tahun 2014, (c) Tahun 2016, (d)

Tahun 2018 dan (e) Tahun 2020 (Sumber : hasil analisis spasial, 2020)

Selanjutnya indikator dari faktor ketinggian adalah dengan mengidentifikasi perubahan /penurunan titik tertinggi yang ada di Kota Tarakan, dari data tersebut diketahui bahwa titik tertinggi yang ada di Kota Tarakan setiap tahunnya mengalami penurunan yang signifikan dengan penurunan ketinggian $\pm 5 \mathrm{~m}$ setiap dua tahun sekali, dapat dilihat pada Gambar 4 dan Tabel 4. Berdasarkan teori dari pengertian erosi maka dua faktor tersebut telah memenuhi kriteria untuk terjadinya potensi bahaya erosi yang ada di kota Tarakan. Berdasarkan hal tersebut maka pengelolaan tanah dan vegetasi mutlak diperlukan dalam meminimalisir terjadinya potensi erosi di suatu wilayah. Dengan melakukan penanaman vegetasi akan menghambat laju aliran permukaan air, selain itu juga pengelolaan tanah dapat dilakukan sebagai upaya agar tanah tetap lestari (Arsyad, 2010).
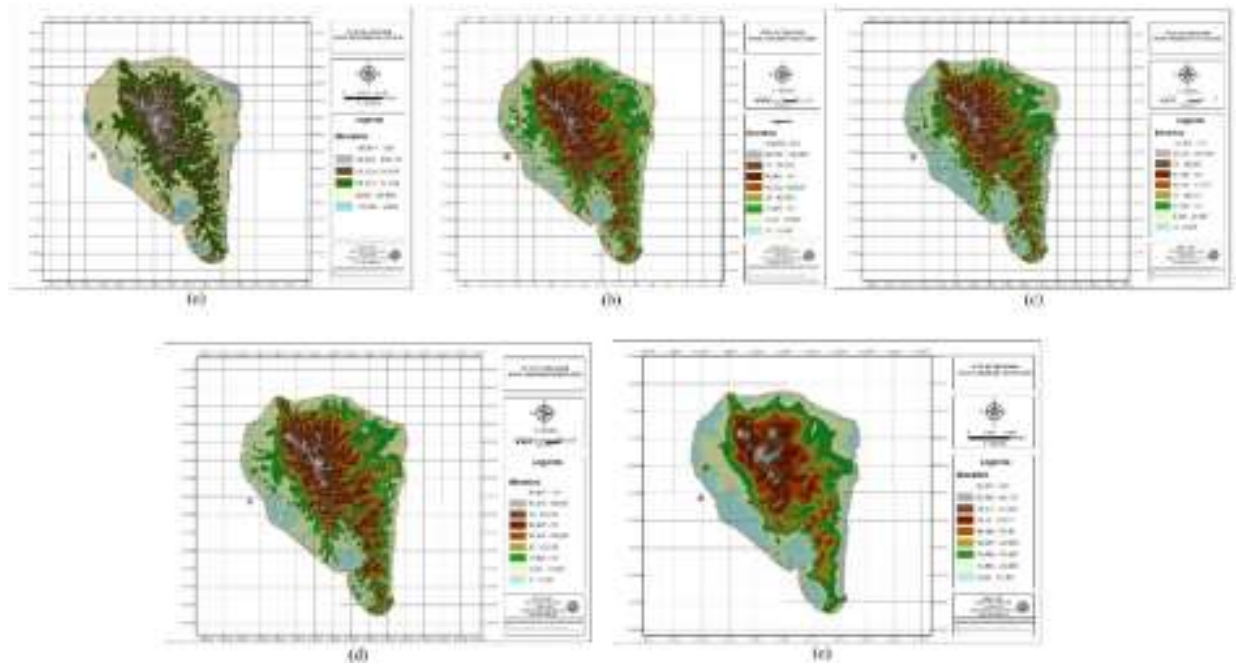

Gambar 4. Peta Ketinggian Kota Tarakan (a) Tahun 2012, (b) Tahun 2014, (c) Tahun 2016, (d) Tahun 2018 dan (e) Tahun 2020 (Sumber : hasil analisis spasial, 2020) 
Tabel 4. Ketinggian Tertinggi di Kota Tarakan

\begin{tabular}{cc}
\hline Tahun & $\begin{array}{c}\text { Ketinggian Tertinggi } \\
(\mathbf{m d p l})\end{array}$ \\
\hline 2012 & 124 \\
\hline 2014 & 118 \\
\hline 2016 & 115 \\
\hline 2018 & 112 \\
\hline 2020 & 107 \\
\hline Sumber : Data olahan analisis raster (2020)
\end{tabular}

\section{KESIMPULAN}

Penggunaan lahan pertanian di Kota Tarakan terdiri atas 4 tipe penggunaan lahan dengan persentase $75,33 \%$ dari luas Kota Tarakan. Penggunaan lahan pertanian tersebut menyebar pada 4 kecamatan yang ada di Kota Tarakan, dengan 10 jenis tutupan lahan. Tarakan Utara dan Tarakan Timur memiliki eksistensi dalam bidang budidaya pertanian secara khusus, terbukti dengan sebaran luas lahan tegalan yang terdapat pada daerah tersebut, untuk Kecamatan Tarakan Barat memiliki potensi pada komoditi perkebunan, sedangkan Tarakan Tengah sebagian besar kawasannya masuk kepada daerah Hutan Lindung kota Tarakan. Potensi bahaya erosi ditunjukkan dengan terjadinya perubahan luas kemiringan lereng setiap dua tahun sekali dalam kurun waktu 10 tahun terakhir serta terjadinya perubahan ketinggian dari 124 mdpl menjadi 107 mdpl.

\section{SARAN}

Pengelolaan lahan pertanian di Kota Tarakan harus mengedepankan pengelolaan lahan secara intensifikasi dengan meminimalisir ekstensifikasi lahan serta mengupayakan aspek konservasi disetiap pengelolaan lahan.

\section{UCAPAN TERIMAKASIH}

Penulis mengucapkan terima kasih kepada Universitas Borneo Tarakan atas dana penelitian DIPA UBT Tahun 2021 yang telah diberikan dan kepada Fakultas Pertanian atas fasilitas yang diberikan selama proses penelitian, sehingga proses penelitian dapat terlaksana dengan baik.

\section{DAFTAR PUSTAKA}

Affan, F. M. (2014). Analisis Perubahan Penggunaan Lahan Untuk Pemukiman Dan Industri Dengan Menggunakan Sistem Informasi Geografis (SIG). Jurnal Ilmiah Pendidikan Geografi, 2(1):49-60.

Arsyad, S. (2010). Konservasi Tanah dan Air. Bogor: IPB Press.
Badan Pusat Statistik (BPS). (2019). Data Produktivitas Pertanian Kalimantan Utara. Kalimantan Utara: BPS.

Badan Standardisasi Nasional. (2014). Klasifikasi Penutup Lahan. Jakarta: BSN.

Departemen Kehutanan. (1986). Petunjuk Pelaksanaan Penyusunan Rencana Teknik Lapangan Rehabilitasi Lahan dan Konservasi Tanah. Jakarta: Departemen Kehutanan.

Dinas Pekerjaan Umum Tarakan (DPUTR). (2020). Data Spasial Kota Tarakan. Tarakan: DPUTR.

Faddel, R. (2019). Analisis Perubahan Penggunaan Lahan Untuk Pemukiman di Kecamatan Tilatang Kamang. Jurnal Kapita Selekta Geografi, 116-125.

Hansen, M., Defries, R., Townshend, J., \& Sohlberg, R. (2000). Global Land Cover Classification at $1 \mathrm{Km}$ Spatial Resolution Using a Classification Tree Approach. International Journal of Remote Sensing.21: 1331-1364

Hidayati, F., Yonariza, Nofialdi, \& Yuzaria, D. (2018). Intensifikasi Lahan Melalui Sistem Pertanian Terpadu. Seminar Nasional Pembangunan Pertanian dan Pedesaan, 1, 113-119.

Indrasmoro, G. P. (2013). Geographic Information System (GIS) Untuk Daerah Rawan Longsor Studi Kasus di Kelurahan Karang Anyar Gunung Semarang. Jurnal GIS Deteksi Rawan Lonsor.

Kartika, I., Indarto, Pudjojono, M., \& Ahmad, H. (2016). Pemetaan Tingkat Bahaya Erosi Pada Level Sub-DAS Studi Pada Dua DAS Identik. Jurnal Agroteknologi. 10(01) : 117-128.

Latuamury, B. (2020). Pemodelan Perubahan Penggunaan Lahan dan Karakteristik Resesi Aliran Dasar Sungai. Yogyakarta: Deepublish.

Mansyur, N. I., Hanudin, E., Purwanto, B. H., \& Utami, S. N. H. (2019). Morphological characteristics and classification of soils formed from acidic sedimentary rocks in North Kalimantan. Ilmu Bumi dan Lingkungan, 1-9. 
Marhendi, T., \& Iskahar. (2017). Pengaruh Faktor Panjang Kelerengan Terhadap Penentuan Awal Erosi Lahan (Vol. 1). Jurnal Riset Sains Teknologi.

Munir, A. (2012). Ilmu Ukur Wilayah dan Sistem Informasi Geografis. Makassar: Kencana.

Prahasta, E. (2009). Konsep-Konsep Dasar Sistem Informasi Geografis Perspektif Geodesi. Bandung: Informatika.

Prahasta, E. (2001). Konsep-Konsep Dasar Sistem Informasi Geografi. Bandung: Informatika.

Puntodewo, A., Dewi, S., \& Tarigan, J. (2003). Sistem Informasi Geografis Untuk Pengelolaan Sumberdaya Alam. Bogor: CIFOR.

Sampurno, R. M., \& Thoriq, A. (2016). Klasifikasi Tutupan Lahan Menggunakan Citra Landsat 8 Operational Land Imager (OLI) di Kabupaten Sumedang . Jurnal Teknotan. 10(2) : 61-70
Sunartomo, A. F. (2011). Inventarisasi dan Sebaran Lahan Kritis di Kabupaten Situbondo. Jurnal Sosial Ekonomi Pertanian Universitas Jember. 5(1) : 12-22

Suseno, A., \& Agus, R. (2012). Penggunaan Quantum GIS Dalam Sistem Informasi Geografis. Bogor.

Syah, M. W., \& Hariyanto, T. (2013). Klasifikasi Kemiringan Lereng Dengan Menggunakan Pengembangan Sistem Informasi Geografis Sebagai Evaluasi Kesesuaian Landasan Pemukiman Berdasarkan Undang-Undang Tata Ruang dan Metode Fuzzy. Jurnal Teknik Pomits. 10(10) : 1-6.

Yumai, Y., Tilaar, S., \& Makarau, V. H. (2019). Kajian Pemanfaatan Lahan Pemukiman di Kawasan Perbukitan Kota Manado. Jurnal Spasial. $\quad$ 6(3): $\quad 862-871$ 